\title{
The Relationship Between EPI and GDP Growth: An Examination on Developed and Emerging Countries
}

\author{
Fatma Tektüfekçi, Nilgün Kutay \\ Dokuz Eylul University, İzmir, Turkey
}

\begin{abstract}
Environmental issues are one of the most important aspects of the long-term development of a country and have an important role in a nation's wealth. Different environmental performance indicators present different methodologies and aim to measure countries' environmental performances with different approaches. One of the environmental indices, Environmental Performance Index (EPI), ranks countries' performance on high-priority environmental issues in two areas: protection of human health and protection of ecosystems. The purpose of this paper is to discuss the environmental aspect of sustainability with the EPI and analyze the relationships and differences of the chosen 14 (seven are developed and seven are emerging) countries' EPI scores and Gross Domestic Products (GDPs).
\end{abstract}

Keywords: environmental performance, Environmental Performance Index (EPI), environmental health, ecosystem vitality, Gross Domestic Product (GDP)

\section{Introduction}

The large number of economic, social, and environmental indicators provides a system of sustainability. The economic theory of sustainable growth that arose in the 1960s marks the beginning of the movement for the preservation of planet Earth, added to the assumption that economic growth must necessarily make sustainable use of available natural resources (García-Sánchez, Das Neves Almeida, \& De Barros Camara, 2015; Dasgupta, Moody, Roy, \& Wheeler, 2001).

Governments and corporations are increasingly being held accountable for their performance on a range of sustainable factors such as pollution control and natural resource management as well as human resources and economic challenges (Roy \& Goll, 2014).

Since industrial activities have contributed negative effects to the natural environment, it is very important to get industry to comply with ecological principles for sustainable development (Roy \& Goll, 2014). As firms experience growing pressure from society, regulations, and competition, they have changed the way they view and interact with the natural environment over time. "A sustainable company is one that can combine corporate survival with the objectives of a sustainable world over the long run" (Roy \& Goll, 2014; Clifton \& Amran, 2011).

Fatma Tektüfekçi, associate professor, Faculty of Economics and Administration Sciences, Business Administration, Accounting and Finance Department, Dokuz Eylul University. Email: f.tektufekci@deu.edu.tr.

Nilgün Kutay, associate professor, Faculty of Economics and Administration Sciences, Business Administration, Accounting and Finance Department, Dokuz Eylul University. 
In this context, countries and organizations have to adopt policies to reduce pollution and improve the quality of life in a sustainable way. Because country performances cannot be limited just with Gross Domestic Products (GDPs), different types of indicators to assess sustainable performances are used in country rankings. With this respect, many sustainability indices have been developed. Some of them are: Ecological Footprint (EF), Environmental Sustainability Index (ESI), Dashboard of Sustainability (DS), Index of Sustainable Economic Welfare (ISEW), City Development Index (CDI), Human Sustainable Development Index (HSDI), Living Planet Index (LPI), Environmentally Adjusted Domestic Product (EDP), Sustainability Society Index (SSI), Well-Being Index (WI), and Environmental Performance Index (EPI).

In our study, first we rank the chosen 14 countries by their 2016 EPI scores, seven of which are developed and seven are emerging countries. Turkey is shown with the scores of each indicator that takes place in 2016 EPI. Then in the research, with statistical tests, relationships and differences between EPI scores and GDPs are analyzed, and EPI scores of developed and emerging countries are compared.

\section{The EPI}

The EPI is a key contributor to the world's increasing ability to assess global environmental movement toward its environmental policy goals.

The EPI ranks countries' performance on high-priority environmental issues in two areas: protection of human health and protection of ecosystems. Within these two policy objectives, the EPI scores national performance in nine issue areas comprised of more than 20 indicators (EPI 2016 Final Report) as seen in Table 1.

Table 1

Statistical Weightings Used for the 2016 EPI

\begin{tabular}{|c|c|c|c|}
\hline EPI & Objective & Issue category & Indicator \\
\hline \multirow{19}{*}{ EPI } & \multirow{7}{*}{$\begin{array}{l}\text { Environmental } \\
\text { health }(50 \%)\end{array}$} & Health impacts $(33 \%)$ & Environmental risk exposure $(100 \%)$ \\
\hline & & \multirow{4}{*}{ Air quality $(33 \%)$} & Household air quality (30\%) \\
\hline & & & Air pollution - Average exposure to PM2.5 (30\%) \\
\hline & & & Air pollution - PM2.5 exceedance (30\%) \\
\hline & & & Air pollution - Average exposure to $\mathrm{NO}_{2}(10 \%)$ \\
\hline & & \multirow{2}{*}{ Water and sanitation $(33 \%)$} & Unsafe sanitation $(50 \%)$ \\
\hline & & & Drinking water quality $(50 \%)$ \\
\hline & \multirow{12}{*}{$\begin{array}{l}\text { Ecosystem vitality } \\
(50 \%)\end{array}$} & Water resources $(25 \%)$ & Wastewater treatment $(100 \%)$ \\
\hline & & \multirow{2}{*}{ Agriculture (10\%) } & Nitrogen use efficiency $(75 \%)$ \\
\hline & & & Nitrogen balance $(25 \%)$ \\
\hline & & Forests $(10 \%)$ & Tree cover loss $(100 \%)$ \\
\hline & & Fisheries $(5 \%)$ & Fish stocks $(100 \%)$ \\
\hline & & \multirow{5}{*}{$\begin{array}{l}\text { Biodiversity and habitat } \\
(25 \%)\end{array}$} & Terrestrial protected areas (national biome weights) $(20 \%)$ \\
\hline & & & Terrestrial protected areas (global biome weights) $(20 \%)$ \\
\hline & & & Marine protected areas $(20 \%)$ \\
\hline & & & Species protection (national) $(20 \%)$ \\
\hline & & & Species protection (global) $(20 \%)$ \\
\hline & & \multirow{2}{*}{ Climate and energy $(25 \%)$} & Trend in carbon intensity $(75 \%)$ \\
\hline & & & Trend in $\mathrm{CO}_{2}$ emissions per KWH $(25 \%)$ \\
\hline
\end{tabular}

Note. Source: EPI (2016a; 2016b). 
Environmental health measures the protection of human health from environmental harm. Ecosystem vitality measures ecosystem protection and resource management. These two objectives are divided into nine issue categories that encompass high-priority environmental policy issues including agriculture, air quality, biodiversity and habitat, climate and energy, forests, fisheries, health impacts, water resources and water and sanitation.

The EPI uses primary and secondary data from multilateral organizations, government agencies, and academic collaborations in calculations. Primary data are composed of information gathered directly by human or technological monitoring, including satellite-derived estimates of forest cover and air quality. Secondary data include national-level statistics subject to the reporting and quality requirements established by data collection entities, such as the International Energy Agency (IEA). ${ }^{1}$

Aligning EPI's indicators with the United Nations Sustainable Development Goals (SDGs) provides a baseline for evaluating national performance and shows how far countries are from reaching global targets (EPI 2016 Final Report).

The EPI's value lies not only in the overall rankings, which are intended to drive productive competition, but also in the issue-by-issue metrics that provide a diagnostic tool for countries to look internally for areas of weakness and strength. A common framework and methodology allows countries to compare their performance with that of neighbors and peers, and through the analysis of time series data, we can see how their own performance has changed over time (EPI 2016 Final Report).

Sima and Georgiana's (2014) analysis of environmental performance in Romania, based on the EPI, shows that sustainable economic growth is an ecological growth, which can be measured by green productivity growth, accompanied by emission reductions, so that this green growth "can fight" against climate change, and cause an increase of the amount of energy coming from renewable sources.

\section{Relationship Between GDP and the EPI}

According to 2016 EPI Report, nearly all countries show improvement in EPI score over the last decade. But countries already at higher levels of performance, including North America and Europe, have not improved nearly as much as developing countries have improved over the last decade.

Both the environmental health and ecosystem vitality objectives demonstrate positive relationships with GDP per capita, suggesting that as wealth increases, national environmental performance improves. The relationship between health and GDP per capita, however, is stronger, which is most likely to be driven by the investments in public health, sanitation, and infrastructure as countries develop. Ecosystem vitality scores are more dispersed in their relationship with GDP per capita. Many wealthy OPEC (Organization of Petroleum Exporting Countries) countries, including Kuwait, Qatar, Oman, and Saudi Arabia, underperform on environmental performance relative to similar economic peers. What the difference in relationship between ecosystem vitality and environmental health scores and GDP per capita suggests is that both wealthy and developing countries alike have room for improvement with respect to ecosystem and natural resource management. As countries develop, more focus and attention is paid to public health and creating management systems for clean water, sanitation, and energy (EPI 2016 Final Report, p. 116).

\footnotetext{
${ }^{1}$ Retrieved from http://www.epi.yale.edu.
} 


\section{Materials and Methods}

In this study, firstly, the 14 chosen countries are ranked by their 2016 EPI scores, and our country Turkey is analyzed with the scores of each indicator that takes place in 2016 EPI.

Secondly, from 2002 to 2013, EPI scores and GDP values of the 14 chosen countries are listed and the relationships and differences of EPI scores and GDPs are analyzed.

We have chosen 14 countries for examination, seven of which are developed (New Zealand, Australia, Switzerland, Norway, the United States of America, Germany, and the Netherlands) and seven are emerging countries (Brazil, Venezuela, South Africa, Turkey, Indonesia, China, and India) as seen in Table 2.

Table 2

2016 EPI Results for the Selected 14 Countries

\begin{tabular}{|l|l|l|l|l|}
\hline Rank & Country & EPI score & The highest score of the indicator & The lowest score of the indicator \\
\hline 11 & New Zealand & 88.00 & Water and sanitation, score is 100 & Fisheries, score is 27.89 \\
\hline 13 & Australia & 87.22 & $\begin{array}{l}\text { Health impacts, } \\
\text { water and sanitation, score is } 100\end{array}$ & Forests, score is 33.92 \\
\hline 16 & Switzerland & 86.93 & Water and sanitation, score is 99.93 & Air quality, score is 72.09 \\
\hline 17 & Norway & 86.90 & Health impacts, score is 100 & Climate and energy, score is 57.12 \\
\hline 26 & United States of America & 84.72 & Agriculture, score is 99.4 & Forests, score is 18.39 \\
\hline 30 & Germany & 84.26 & Biodiversity and habitat, score is 100 & Fisheries, score is 34.04 \\
\hline 36 & The Netherlands & 82.03 & Water resources, score is 99.65 & Fisheries, score is 28.64 \\
\hline 48 & Brazil & 78.90 & Biodiversity and habitat, score is 92.62 & Forests, score is 37.86 \\
\hline 56 & Venezuela & 76.23 & Biodiversity and habitat, score is 95.73 & Fisheries, score is 14.09 \\
\hline 81 & South Africa & 70.52 & Agriculture, score is 93.4 & Forests, score is 0 \\
\hline 99 & Turkey & 67.68 & Agriculture, score is 87.04 & Biodiversity and habitat, score is 22.53 \\
\hline 107 & Indonesia & 65.85 & Agriculture, score is 84.31 & Water resources, score is 12.69 \\
\hline 109 & China & 65.10 & Water and sanitation, score is 85.54 & Air quality, score is 23.81 \\
\hline 141 & India & 53.58 & Forests, score is 74.8 & Air quality, score is 28.07 \\
\hline
\end{tabular}

Note. Source: EPI (2016c).

New Zealand, Australia, Switzerland, Norway, the United States of America, Germany, and the Netherlands, which are developed countries, have higher EPI scores. Brazil, Venezuela, South Africa, Turkey, Indonesia, China, and India, which are emerging countries, have lower EPI scores. Each country's lowest and highest indicator scores are also listed in Table 2.

In developed countries, the following indicators have the highest scores:

(1) Water sanitation;

(2) Health impacts;

(3) Biodiversity and habitat;

(4) Water resources;

(5) Agriculture.

Building on the expired Millennium Development Goals, the United Nations SDG includes targets, "universal access to safe and affordable drinking water", and "adequate and equitable sanitation". Access to safe drinking water is critical for promoting human health, socioeconomic development, and individual well-being. As nations become wealthier, their governments invest in infrastructure which generally led to improved public health. So in developed countries, governments give more importance to the indicators listed above. 
In developed countries, the indicators of fisheries, forests, climate and energy, and air quality have the lowest scores, but fisheries and forests data are extraordinarily poor. The oceans in 2015 contain half the fish that they did in 1970, and overfishing is the primary cause of this collapse. Illegal fishing, inadequate science and excessive catch limits have created overexploitation. The 2016 EPI calculates overall tree cover loss from 2000 to 2014 in areas with greater than $30 \%$. Unsustainable timber harvesting, urban sprawl, agricultural expansion, mining and mineral exploitation threaten global forests.

In emerging countries, the following indicators have the highest scores, but especially biodiversity habitat and agriculture have better scores:

(1) Biodiversity and habitat;

(2) Agriculture;

(3) Forests;

(4) Water and sanitation.

Many countries show improvements in terrestrial and marine habitat protection in 2016 EPI. The number of protected areas that national governments have designated has doubled each decade for the last 20 years.

Starting in the middle of the 20th century, the use of synthetic fertilizers and the implementations of "Green Revolution" boosted agricultural production around the world, and emerging countries have given special importance to this indicator. From local to global scales, agriculture influences all major environmental issues: soil quality, water quality, air quality, carbon pollution, and climate change.

In emerging countries, the following indicators have the lowest scores:

(1) Forests;

(2) Water resources;

(3) Fisheries;

(4) Biodiversity and habitat;

(5) Air quality.

The indicators of forests, fisheries, and air quality have low scores for both developed and emerging countries.

Rapid industrialization and urbanization has resulted in much of the world, in badly polluted air. Human health metrics confirm the toxic air's pernicious effects, in China for instance, one in five deaths are attributed to air pollution.

Between 180 countries whose EPI scores are calculated, Turkey is on the 99th rank. Table 3 shows the scores and the ranks of each indicator for Turkey that takes place in 2016 EPI.

For Turkey, indicator of "fisheries" has the highest rank (35) with the score of 57.82. Because Turkey is a peninsula, three sides are covered with seas, fisheries plays an important role in its economy. Once fish stocks collapse, they require long-term protection to recover. When a fishery collapses, the loss creates a trophic cascade that alters marine ecosystems and prevents fish populations from rebuilding.

For Turkey, indicator of "biodiversity and habitat" has the lowest rank (177) with a score of 23.53. The five "biodiversity and habitat" indicators describe national effort measured in area for biome protection as well as effectiveness measured in biodiversity - at protecting wildlife, providing dept and utility to the category. As seen in Table 3, between the five categories of this indicator, the highest score is 57.48 for "marine protected areas". 
Table 3

Scores and Ranks Indicators of EPI 2016 for Turkey

\begin{tabular}{|c|c|c|c|c|}
\hline Name of indicator & Score & Rank & $\begin{array}{l}\text { Compared to GDP } \\
\text { peer set }(\%)\end{array}$ & $\begin{array}{l}\text { Compared to region } \\
\text { peer set }(\%)\end{array}$ \\
\hline Health impacts & 74.43 & 81 & -4.21 & -9.64 \\
\hline Environmental risk exposure & 74.43 & 81 & -4.21 & -9.64 \\
\hline Air quality & 79.3 & 98 & -5.56 & -0.21 \\
\hline Air pollution - Average exposure to nitrogen dioxide & 53.72 & 150 & -32.13 & -24.61 \\
\hline Air pollution - Average exposure to PM2.5 & 78.61 & 103 & -3.54 & 1.82 \\
\hline Household air quality & 91.76 & 74 & 4.35 & 2.52 \\
\hline Air pollution - PM2.5 exceedance & 76.07 & 125 & -9.54 & 2.2 \\
\hline Water and sanitation & 85.06 & 71 & 5.97 & 2.15 \\
\hline Unsafe sanitation & 86.84 & 65 & 6.88 & 6.27 \\
\hline Drinking water quality & 83.28 & 75 & 5.04 & -1.82 \\
\hline Water resources & 78.99 & 53 & 34.98 & 36.54 \\
\hline Wastewater treatment & 78.99 & 53 & 34.98 & 36.54 \\
\hline Agriculture & 87.04 & 86 & 20.3 & -1.55 \\
\hline Nitrogen use efficiency & 82.72 & 94 & 13.53 & -8.45 \\
\hline Nitrogen balance & 100 & 1 & 41.18 & 21.15 \\
\hline Forests & 68.48 & 40 & 11.1 & -8.53 \\
\hline Tree cover loss & 68.48 & 40 & 11.1 & -8.53 \\
\hline Fisheries & 57.82 & 35 & 23.06 & 6.46 \\
\hline Fish stocks & 57.82 & 35 & 23.06 & 6.46 \\
\hline Biodiversity and habitat & 23.53 & 177 & -68.28 & -65 \\
\hline Terrestrial protected areas (national biome weights) & 17.29 & 177 & -75.94 & -72.9 \\
\hline Terrestrial protected areas (global biome weights) & 17.29 & 177 & -76.49 & -73.86 \\
\hline Species protection (national) & 13.97 & 178 & -79.87 & -76.8 \\
\hline Species protection (global) & 6.602 & 179 & -90.76 & -89.19 \\
\hline Marine protected areas & 57.48 & 101 & -19.56 & -30.65 \\
\hline Climate and energy & 47.77 & 1 & -30.07 & -39.02 \\
\hline Access to electricity & 100 & 1 & 4.66 & 0 \\
\hline Trend in $\mathrm{CO}_{2}$ emissions per $\mathrm{KWH}$ & 54.69 & 164 & -30.93 & -32.98 \\
\hline Trend in carbon intensity & 54.93 & 104 & -25.48 & -30.13 \\
\hline $\mathrm{CO}_{2}$ emissions per unit $\mathrm{KWH}$ & 54.69 & 164 & -30.93 & -32.98 \\
\hline
\end{tabular}

Note. Source: EPI (2016c).

As fisheries indicator has the highest rank, the marine protected areas indicator with the best score for the indicator "biodiversity and habitat" is very expressive. The marine protected areas indicator reports the protected proportion of a country's exclusive economic zone.

The first four categories of the indicator place national efforts to protect habitat and species in global context, showing the significance of a country's policies at the global scale, though they are rough proxies for species loss prevention and habitat quality conservation. For Turkey, the scores of the first four categories of the indicator "biodiversity and habitat" are very low.

On January 27, a Turkish reporter for the Dogan News Agency wrote about Turkey's low ranking in the 2016 Yale EPI. Two days later, Dogan News published "Turkey on the Bottom”, an exposé bemoaning Turkey's "retrogressive decade" of environmental performance that pushed the country's Climate \& Energy and Biodiversity \& Habitat index scores below those of Iraq, Syria, Libya, and Haiti. Ministry's General Directorate 
described EPI's Biodiversity \& Habitat data as "untenable", "unfounded", "misleading”, "unreliable", "open to debate", and "in need of explanation" (Mosteller, 2016).

In the second part of the research, for 14 countries (seven of which are developed and seven are emerging countries), EPI scores and GDP values from 2002 to 2013 are used. ${ }^{2}$ First; to show the relationship between EPI scores and GDP values of the 14 countries, Spearman rank correlation analysis is used.

H0: There is not a significant relationship between EPI scores and GDPs of the countries.

H1: There is a significant relationship between EPI scores and GDPs of the countries.

According to Spearman rank correlation analysis (see Table 4), there is a significant relationship between EPI scores and GDPs. Because $p=0.001<0.05=\alpha, \mathrm{H} 0$ is rejected and $\mathrm{H} 1$ is accepted.

Table 4

Spearman Rank Correlation

\begin{tabular}{|c|c|c|c|c|}
\hline Spearman rank correlation & & & EPI & GDP \\
\hline \multirow{6}{*}{ Spearman's rho } & \multirow{3}{*}{ EPI } & Correlation coefficient & 1.000 & $-0.793^{* *}$ \\
\hline & & Sig. (2-tailed) & & 0.001 \\
\hline & & $N$ & 14 & 14 \\
\hline & \multirow{3}{*}{ GDP } & Correlation coefficient & $-0.793^{* *}$ & 1.000 \\
\hline & & Sig. (2-tailed) & 0.001 & \\
\hline & & $N$ & 14 & 14 \\
\hline
\end{tabular}

Note. ${ }^{* *}$ : Correlation is significant at the 0.01 level (2-tailed).

Between EPI scores and GDPs of the countries, there is a relationship, strong, but on the reverse (negative) direction (correlation coefficient $=-0.793$ ). It means that if GDPs of the countries get higher, the EPI scores get lower.

In the second step, Wilcoxon signed-rank test is used to show the significant difference between EPI scores and GDPs of the countries. Before using this test, EPI and GDP values are normalized by dividing the values to column total.

Table 5

Wilcoxon Signed-Rank Test

\begin{tabular}{ll}
\hline Wilcoxon signed-rank test statistics & \\
\hline & GDP_norm - EPI_norm \\
\hline$Z$ & $-0.408^{\mathrm{a}}$ \\
Asymp. sig. (2-tailed) & 0.683 \\
\hline
\end{tabular}

Note. ${ }^{\text {a: }}$ Based on positive ranks.

H0: There is not a significant difference between EPI scores and GDPs of the countries.

H1: There is a significant difference between EPI scores and GDPs of the countries.

According to Wilcoxon signed-rank test, there is not a significant difference between EPI scores and GDPs of the countries. Because $p=0.683>0.05=\alpha, \mathrm{H} 0$ is accepted and $\mathrm{H} 1$ is rejected.

In the third step, Mann-Whitney U test is used to show the difference between the EPI scores of developed countries and the EPI scores of emerging countries.

H0: There is not a significant difference between the EPI scores of developed countries and the EPI scores of emerging countries.

${ }^{2}$ Retrieved from http://epi.yale.edu; http://databank.worldbank.org/data. 
H1: There is a significant difference between the EPI scores of developed countries and the EPI scores of emerging countries.

According to the Mann-Whitney U test (see Table 6), there is a statistically significant difference between EPI scores of developed and emerging countries. Because $p=0.002<0.05=\alpha, \mathrm{H} 0$ is rejected and $\mathrm{H} 1$ is accepted.

As seen in table of ranks, developed countries' mean rank is higher than the emerging countries' mean rank.

Table 6

Mann-Whitney U Test

\begin{tabular}{|c|c|c|c|c|}
\hline \multicolumn{5}{|c|}{ Mann-Whitney U test statistics ${ }^{\mathrm{a}}$} \\
\hline \multicolumn{5}{|c|}{ EPI } \\
\hline \multicolumn{2}{|c|}{ Mann-Whitney U } & \multicolumn{2}{|c|}{0.000} & \\
\hline \multicolumn{2}{|c|}{ Wilcoxon W } & \multicolumn{2}{|c|}{28.000} & \\
\hline \multicolumn{2}{|l|}{$\mathrm{Z}$} & \multicolumn{2}{|c|}{-3.130} & \\
\hline \multicolumn{2}{|c|}{ Asymp. sig. (2-tailed) } & \multicolumn{2}{|c|}{0.002} & \\
\hline \multicolumn{2}{|c|}{ Exact sig. [2*(1-tailed sig.)] } & \multicolumn{2}{|c|}{$0.001^{\mathrm{b}}$} & \\
\hline Rank & Country & $N$ & Mean rank & Sum of ranks \\
\hline \multirow{3}{*}{ EPI } & Developed countries & 7 & 11.00 & 77.00 \\
\hline & Emerging countries & 7 & 4.00 & 28.00 \\
\hline & Total & 14 & & \\
\hline
\end{tabular}

Note. ${ }^{a}$ : Grouping variable: Countries. ${ }^{b}$ : Not corrected for ties.

\section{Conclusion}

Sustainability is a normative notion that indicates the way how humans should act towards nature and how they are responsible towards one another and future generations (Baumgärtner \& Quass, 2010). The large number of economic, social, and environmental indicators provides a view of system sustainability.

Focusing on environmental indicators, EPI quantifies and numerically benchmarks the environmental performance of a country's policies that can be more easily used by policymakers, environmental scientists, advocates and the general public (Mondejar-Jimenez, Alfaro-Navarro, \& Andrés-Martínez, 2014). The EPI is a comparative tool to judge environmental performance between nations, and also highlights global trends in environmental performance and measurement.

In our research, first, the chosen 14 countries are analyzed. Seven developed and seven emerging countries are ranked by their 2016 EPI scores. It is seen that the seven developed countries have higher 2016 EPI scores than the seven emerging countries, and then our country Turkey, which is emerging, is analyzed by each indicator score in 2016 EPI and it is seen that "fisheries" with the score of 57.82 is in the first rank, and the indicator "biodiversity and habitat" with the score of 23.53 is in the last rank.

Then, in the research with the Spearman rank correlation, it is found that there is a strong relationship between EPI scores and GDPs of the countries, but on the reverse direction. With Wilcoxon signed-rank test, it is found that there is not a significant difference between EPI scores and GDPs of the countries.

And finally, with the Mann-Whitney U test, it is seen that there is a significant difference between the EPI scores of developed and emerging countries. Developed countries have higher mean rank than emerging countries. 
In developed countries, the sustainability focuses on environmental topics more than emerging countries. With strict environmental protection laws, wealthy countries use pollution-intensive materials and products to keep their domestic environment in better condition.

\section{References}

Baumgärtner, S., \& Quass, M. (2010). What is sustainability economics? Ecological Economics, 69, 445-450.

Clifton, D., \& Amran, A. (2011). The stakeholder approach: A sustainability perspective. Journal of Business Ethics, 98(1), 121-136.

Dasgupta, S., Moody, A., Roy, S., \& Wheeler, D. (2001). Environmental regulation and development: A cross-country empirical analysis. Oxford Development Studies, 29(2), 173-187.

EPI 2016 Final Report. (2016). Global metrics for the environment: The Environmental Performance Index (EPI) ranks countries' performance on high-priority environmental issues. Retrieved from http://epi.yale.edu/sites/default/files/EPI2016_FINAL\%20REPORT.pdf

EPI. (2016a). 2016_epi_framework_indicator_scores_friendly_0. Yale Data-Driven Environmental Group Yale University and Center for International Earth Science Information Network (CIESIN) Columbia University. Retrieved from http://epi.yale.edu/downloads

EPI. (2016b). 2016epi_weightings_0. Retrieved from http://epi.yale.edu/downloads

EPI. (2016c). Retrieved from http://epi.yale.edu/country-rankings

García-Sánchez, I. M., Das Neves Almeida, T. A., \& De Barros Camara, R. P. (2015). A proposal for a composite index of environmental performance (CIEP) for countries. Ecological Indicators, 48, 171-188.

Mondejar-Jimenez, J. A., Alfaro-Navarro, J. L., \& Andrés-Martínez, E. (2014). A review on the main countries' environmental rankings. International Journal of Environmental Research, 8(4), 1279-1286.

Mosteller, D. (March 9, 2016). "Yale's lies?" EPI's rankings ignite national controversy in Turkey. Retrieved from http://www.sagemagazine.org/turkey-2016-epi/

Roy, A., \& Goll, I. (2014). Predictors of various facets of sustainability of nations: The role of cultural and economic factors. International Business Review, 23(5), 849-861.

Sima, V., \& Georgiana, G. I. (2014). Analyze of environmental performance in Romania based on environmental performance index. Annals of the "Constantin Brâncuşi”" University of Târgu Jiu, Economy Series, Issue 3 (2014), "Academica Brâncuşi”" Publisher.

World Bank. (2015). Data_Extract_From_World_Development_Indicators. Retrieved from http://databank.worldbank.org/data 